\title{
Relationship between psychological factors and performance- based and self-reported disability in chronic low back pain
}

\author{
H. R. Schiphorst Preuper $\cdot$ M. F. Reneman • \\ A. M. Boonstra · P. U. Dijkstra · G. J. Versteegen • \\ J. H. B. Geertzen $\cdot$ S. Brouwer
}

Received: 4 February 2008/Revised: 9 June 2008/Accepted: 28 August 2008/Published online: 16 September 2008

(C) The Author(s) 2008. This article is published with open access at Springerlink.com

\begin{abstract}
Cross sectional study, performed in an outpatient university based pain rehabilitation setting. To analyze the relationship between psychological factors (psychosocial distress, depression, self efficacy, selfesteem, fear of movement, pain cognitions and coping reactions) and performance-based and self-reported
\end{abstract}

H. R. Schiphorst Preuper ( $\square) \cdot$ M. F. Reneman •

P. U. Dijkstra · J. H. B. Geertzen - S. Brouwer

Center for Rehabilitation, University Medical Center Groningen,

University of Groningen, PO Box 30.002, 9750 RE Haren,

Groningen, The Netherlands

e-mail: h.r.schiphorst.preuper@cvr.umcg.nl

H. R. Schiphorst Preuper - M. F. Reneman ·

P. U. Dijkstra · J. H. B. Geertzen · S. Brouwer

Graduate School for Health Research SHARE,

University Medical Center Groningen,

University of Groningen, Groningen, The Netherlands

A. M. Boonstra

Center for Rehabilitation, 'Revalidatie Friesland',

Beetsterzwaag, The Netherlands

P. U. Dijkstra

Department of Oral and Maxillofacial Surgery,

University Medical Center Groningen,

University of Groningen, Groningen, The Netherlands

G. J. Versteegen

Pain Expertise Center, University Medical Center Groningen,

University of Groningen,

Groningen, The Netherlands

S. Brouwer

Department of Health Sciences,

University Medical Center Groningen,

University of Groningen, Groningen, The Netherlands disability, as measured with a Functional Capacity Evaluation (FCE) and the Roland Morris Disability Questionnaire (RMDQ), in patients with chronic low back pain (CLBP). It has been suggested that a strong relationship exists between psychological factors and disability in patients with CLBP. In former research disability was often measured by self-report and seldom performance-based. Study sample consisted of 92 patients with CLBP admitted for multidisciplinary rehabilitation. Prior to treatment, all patients completed questionnaires to measure psychological factors and self-reported disability, and performed an FCE to measure performance-based disability. Correlation coefficients between psychological variables and FCE and self-reported disability were calculated. Multivariate linear regression analyses were performed with self-reported or performance based disability measures as outcome variables, and psychological measures as predictor variables. Out of 42 relations analyzed, 5 were statistically significant. This concerned one significant correlation between kinesiophobia and a subtest of FCE, and four correlations between psychological factors and RMDQ. No correlation was significant after the Bonferroni correction was applied $(P<0.001)$. The strength of significant correlations ranged from $r=-0.33$ to $r=0.25$. The multivariate analysis revealed that psychological variables measured in this study could explain $19 \%$ of the variance of self-reported disability, with kinesiophobia being the only psychological variable that contributed significantly. The suggested strong relationship between psychological factors and performance-based and selfreported disability could not be confirmed in this study. This may implicate that the relationship between psychological factors and disability in patients with CLBP is not as unambiguous as suggested. 
Keywords Disability - Psychological questionnaires . Functional capacity evaluation - Roland Morris Disability Questionnaire · Performance test - Chronic low back pain

\section{Introduction}

A major issue in pain rehabilitation programs for chronic low back pain (CLBP) is the suggested relation between psychological factors and disability. This relationship is stressed in dominant models such as the bio-psychosocial model [57, 65], and the fear avoidance model [62, 63]. According to the bio-psychosocial model, patient's functioning is influenced by biological, psychological and social factors. Psychological factors such as distress (depression, anxiety, and fear), self-efficacy, fear-avoidance beliefs, coping styles and cognitive factors generally are presumed to have a substantial impact on back pain disability rather than biomedical or biomechanical factors [29, 30, 39, 43].

In several studies the relationship between psychological factors and disability in patients with CLBP has been investigated [43, 57, 65]. Most of these studies were performed with the use of questionnaires. In these studies contradicting results were found. Some studies showed significant relationships of moderate strength between psychological factors and self-reported disability [39, 44]. In other studies, however, this relationship could not be confirmed, as evidenced by weak correlations between psychological factors and self-reported disability in patients with CLBP [22, 47, 53].

The use of disability questionnaires, while inexpensive, practical and useful to measure self-reported disability, yields information that may not necessarily reflect the real capacity and disability in daily functioning [55]. In order to assess physical capacity, performance tests were introduced in rehabilitation practice over the last years. Assessing disabilities using different perspectives such as the patient and performance testing may lead to differences in disability assessed and in relationship between psychological factors and disability. Several studies demonstrated that the outcomes of both types of measures (self-report and performance tests) differ distinctly and correlate weakly to moderately $[14,25,37,46]$. In some studies the relation between psychological factors and performance-based disability has been investigated [36, $47,50,55,62]$. The results of these studies, however, remain inconclusive because they focus on one or a few psychological factor(s) only, or use only one type of instrument (for example lifting or bicycling) to measure disability. The aim of this study was to further investigate the relationship between psychological factors and performance-based next to self-reported disability in a sample of patients with CLBP.

\section{Materials and methods}

\section{Patients}

Ninety-two consecutive patients, who were referred for a multidisciplinary pain management program in the Center for Rehabilitation, University Medical Center Groningen, the Netherlands, and who agreed to participate, were included in this study. All patients had CLBP lasting longer than 3 months. Patients were referred by general physicians or medical specialists. All patients had signed informed consent. This study was part of a larger research program LOBADIS (Low Back Pain and Disability), funded by the Dutch government; ZonMw grant number 9606-006. Inclusion criteria were: CLBP longer than 3 months, age between 18 and 65 years, and still at work, on modified work, or less than 1-year out of work due to CLBP. Exclusion criteria were: CLBP with an underlying specific medical cause, co-morbidity with severe negative consequences for physical and/or mental functioning (for example severe psychiatric disease), addiction to drugs, and insufficient knowledge of the Dutch language.

\section{Procedures}

Prior to the treatment program patients completed questionnaires assessing demographic data, patient's characteristics, disability and psychological variables. Additionally, patients performed tests according to the WorkWell Functional Capacity Evaluation (FCE) [48]. The study was approved by the Medical Ethical Committee of the University Medical Center Groningen.

\section{Measures}

Demographic variables (age, gender, education level) and patient characteristics (duration of current complaints, recurrences) were assessed with a self constructed questionnaire. A $100 \mathrm{~mm}$ Visual Analogue Scale (VAS) was used to measure current pain intensity, ranging from no pain $(0 \mathrm{~mm})$ to unbearable pain $(100 \mathrm{~mm})$.

Psychosocial distress was measured with the Symptom Checklist-90-Revised (SCL-90-R; 90 items). The total score, the Global Severity Index (GSI) reflects the severity of all answered statements as a global measure of mental and physical distress. Scores range from 90 to 450 [3]. Higher scores indicate higher levels of distress. Reliability and validity of the SCL-90-R are good $[3,6,18,41]$. 
Depression was measured with the Dutch version of the Beck Depression Inventory (BDI; 21 items). Scores range from 0 to 63 [5]. The BDI is an efficient screening device for depression in patients with CLBP [40]. Reliability and validity are satisfactory $[5,9,11]$.

Self efficacy was measured with the Dutch version of the General Self Efficacy Scale (Algemene Competentie Schaal; ALCOS-Short Form). The ALCOS-SF measures the subject's expectations of their capacities in general (17 items). Scores range from 100 (lowest) to 500 (highest self efficacy). The reliability and construct validity of the ALCOS-SF are satisfactory [10]. A validated Dutch-language pain-specific self efficacy measure was not available during this study.

Self-esteem was measured with the Dutch version of the Rosenberg Self-Esteem Scale (SES). Scores range from 1 (lowest) to 40 (highest) [8]. It consists of ten items, five of them positively worded and five negatively worded. A positively worded item is for example: 'I feel good about myself'. A negatively worded item is for example: 'I certainly feel useless at times' [56]. Reliability and construct validity are satisfactory [8].

Fear of movement and (re) injury was measured with the Dutch version of the Tampa Scale of Kinesiophobia (TSK). The questionnaire consists of 17 items scored on a 4-point scale. Scores range from 17 (low fear) to 68 (high fear). Reliability and validity of the Dutch version are good [23, 62].

Pain cognitions were measured with the Pain Cognition List, experimental version (PCL-E). The PCL-E measures the verbal-cognitive response system of pain in five subscales. Each item presents a specific pain cognition statement, for example 'My thoughts are always concentrated on the pain' and the patient is asked to indicate agreement or disagreement on a 5-point Likert scale. ( $1=$ totally disagree; $5=$ totally agree). The following subscales are distinguished: pain impact (17 items, subscale scores ranging from 17 to 85 ), catastrophizing (17 items, subscale scores ranging from 17 to 85 ), outcome efficacy ( 7 items, subscale scores ranging from 7 to 35 ), acquiescence (4 items, subscale scores ranging from 4 to 20 ), and reliance on health care (5 items, subscale scores ranging from 5 to 25$)$. Reliability and validity are sufficient $[60,61,64]$.
Coping reactions were measured with the Utrecht's Coping List (UCL). Scores range from 47 (lowest) to 188 (highest). The following subscales are distinguished: palliative reaction, active coping, social support, avoidance, expression of emotions, passive coping, and coping self statements. Reliability and validity are moderate to good [54].

To assess disability both a performance test as well as a questionnaire was used.

Performance-based disability was measured with the WorkWell FCE, formerly known as the Isernhagen Work Systems (IWS) FCE. An FCE is a battery of tests that measure the ability to perform work-related activities that are used in disability assessments [16]. Although near full FCEs were performed, to assess the ability to perform work related activities specific for patients with CLBP, only lowback related subtests from the FCE were selected for analyses: lifting, carrying two handed and static forward bent test (Table 1) [32, 48]. In patients with CLBP, the lifting tests appear to be the single most important tests, as it is largely predictive of the performance of other test items [26, 27]. Test-retest reliability of these subtests has been established in patients with CLBP [12, 24, 48]. All patients were tested by a physiotherapist, who was trained, certified and experienced in administering FCEs.

Self-reported disability for activities of daily living was measured with the Roland Morris Disability Questionnaire (RMDQ), a widely used health status measure to assess self-reported disability due to low back pain. The RMDQ consists of 24 items. Total scores range from 0 , representing no disability, to 24 , representing severe disability [51, 52]. Construct validity, internal consistency and reproducibility of the RMDQ are good [7, 59]. The Dutch version of the RMDQ has proven to be a reliable instrument to measure self-reported functional status in CLBP patients [13].

\section{Statistical analysis}

All statistical analyses were performed with SPSS. Firstly, a missing data analysis was performed on the SCL-90-R and the RMDQ to ensure completeness of the questionnaires [35]. Missing items of the SCL-90-R were substituted by means of the remaining items of the dimensions. The
Table 1 Description of the activities of the WorkWell Functional Capacity Evaluation (FCE) used in this study

\begin{tabular}{lll}
\hline FCE activity & Description & Scoring \\
\hline Lifting & 5 lifts from table to floor vice versa; & Maximum amount lifted $(\mathrm{kg})$ \\
& $4-5$ weight increments; $<90 \mathrm{~s}$ & \\
Short carry two handed & 5 carries of $1.5 \mathrm{~m}$ vice versa; waist height; & Maximum amount carried $(\mathrm{kg})$ \\
& $4-5$ weight increments; $<90 \mathrm{~s}$ & \\
Static forward bend test & $\begin{array}{c}\text { Standing with } 30-60^{\circ} \text { trunk flexion; } \\
\text { manipulating nut/bolts }\end{array}$ & $\begin{array}{c}\text { Time position is held }(\mathrm{s}) . \\
\text { Maximum of } 15 \text { min }(900 \mathrm{~s})\end{array}$ \\
\hline
\end{tabular}


substitution criterion used here allowed the substitution of, at the most, one missing item for five completed ones. For the RMDQ the total number of missing items was corrected using the following formula: sum score RMDQ $=$ [total yes/(24 - missing $)] \times 24$. Secondly, the distribution of the data was checked for normality (Kolmogorov-Smirnov Test). Depending on the distribution of the data, a $t$ test or a Mann-Whitney test was used to test differences in scores (questionnaires) or performances (FCE) between males and females. Depending on normality Pearson's or Spearman's correlation coefficients were used to express the relationships between psychological questionnaires and the FCEtests and the RMDQ. Multivariate linear regression (method: enter) analyses were performed with self-reported or performance based disability measures as outcome variables, and psychological measures as predictor variables. Based on the univariate relationships, predictor variables were only entered in the model when $P<0.10$. Interpretation of correlation coefficients: $r \leq 0.49$ $\left(r^{2}<24 \%\right)$ : weak relationship, $0.50 \leq \mathrm{r} \leq 0.74$ $\left(25 \%<r^{2}<55 \%\right)$ : moderate relationship, and $r \geq 0.75$ $\left(r^{2}>55 \%\right)$ : strong relationship [45]. A two-tailed significance level was set at $\alpha=0.05$. A Bonferroni correction was applied to reduce type I error in interpreting the data (0.05 divided by 42 ) correlation analyses: $\alpha=0.001$.

\section{Results}

Sample characteristics

The study sample consisted of 92 patients, of which $65 \%$ $(n=60)$ were male. Mean age of the patients was 38.5 years (SD 8.7). The duration of the current low back pain episode was not normally distributed; median was 52 weeks (interquartile range 24-150). In 91\% of the patients the LBP was recurrent. The mean current VAS was $50 \mathrm{~mm}$ (SD $21.5 \mathrm{~mm}$ ). Sixty five percent of the patients had completed lower level education only (primary school, lower vocational education), $35 \%$ were higher educated (intermediate vocational, higher vocational or university education). Twelve percent of the patients were single, $88 \%$ were married or living together.

\section{Psychological and disability status}

The results of the psychological measures, as well as the performance-based and self-reported disability measures are presented in Table 2. The scores on most questionnaires were normally distributed, except for duration of low back pain episode, the subscales expression of emotions and passive coping of the UCL and the static forward bend test of the FCE. Due to an administrative problem in the
Table 2 Descriptive statistics of variables measured in 92 patients with chronic low back pain

\begin{tabular}{|c|c|c|}
\hline Variable & $n$ & Mean (SD) \\
\hline \multicolumn{3}{|l|}{ Psychological variables } \\
\hline SCL-90-R & 86 & $123.3(26.6)$ \\
\hline BDI & 82 & $7.3(5.7)$ \\
\hline ALCOS-SF & 88 & $69.6(9.1)$ \\
\hline SES & 86 & $33.5(4.2)$ \\
\hline TSK & 85 & $36.4(5.6)$ \\
\hline \multicolumn{3}{|l|}{ PCL } \\
\hline Pain impact & 70 & $43.8(8.0)$ \\
\hline Catastrophizing & 71 & $40.2(11.4)$ \\
\hline Outcome efficacy & 71 & $20.2(4.0)$ \\
\hline Acquiescence & 69 & $8.9(2.5)$ \\
\hline Reliance on health care & 71 & $19.2(3.4)$ \\
\hline \multicolumn{3}{|l|}{ UCL } \\
\hline Palliative reaction & 73 & $17.0(3.0)$ \\
\hline Active coping & 71 & $18.3(2.8)$ \\
\hline Social support & 73 & $12.7(2.9)$ \\
\hline Avoidance & 73 & $15.2(2.5)$ \\
\hline Expression of emotions $^{\mathrm{a}}$ & 73 & $6(5-6.5)$ \\
\hline Passive coping ${ }^{\mathrm{a}}$ & 73 & $10(9-11.5)$ \\
\hline Coping self statements & 73 & $11.9(2.7)$ \\
\hline \multicolumn{3}{|l|}{ Disability } \\
\hline Lifting performance $(\mathrm{kg})$ & 92 & $27.8(14.7)$ \\
\hline Men & 60 & $32.5(15.4)$ \\
\hline Women & 32 & $18.8(7.8)$ \\
\hline Carrying performance $(\mathrm{kg})$ & 88 & $31.8(16.4)$ \\
\hline Men & 56 & $35.9(17.4)$ \\
\hline Women & 32 & $24.4(11.4)$ \\
\hline Forward bending performance $(\mathrm{s})^{\mathrm{a}}$ & 91 & $156(108-273)$ \\
\hline $\operatorname{Men}^{\mathrm{a}}$ & 59 & $173(86-273)$ \\
\hline Women $^{\mathrm{a}}$ & 32 & $149(115-278)$ \\
\hline RMDQ & 92 & $12.6(4.8)$ \\
\hline Men & 60 & $12.7(5.0)$ \\
\hline Women & 32 & $12.5(4.5)$ \\
\hline
\end{tabular}

SCL-90-R Symptom Checklist-90- Revised, BDI Beck Depression Inventory, ALCOS-SF General Self Efficacy Scale-Short Form, SES Rosenberg Self Esteem Scale, TSK Tampa Scale of Kinesiophobia, $P C L-E$ Pain Cognition List, experimental version, UCL Utrecht's Coping List, $R M D Q$ Roland Morris Disability Questionnaire

${ }^{a}$ Due to a skewed distribution, median and interquartile range are presented

start of the study, twenty-one patients $(23 \%)$ did not fill out the PCL, and of these patients 19 (21\%) did not fill out the UCL as well. A missing data analysis revealed that the characteristics of those patients who did not fill out the PCL and the UCL ( $n=19-21$; non-responders) did not differ significantly from responders with regards to age, gender, duration of complaints, VAS pain and RMDQ $(n=71)$, indicating that systematic differences between 
responders and non-responders did not occur. Differences between males and females were non-significant in forward bending performances $(P=0.48)$ and the RMDQ $(P=0.43)$, and were significant in lifting the lifting and carrying performances (both $P<0.01$ ).

Relation between psychological variables and disability

The correlation coefficients between psychological variables and disability measures are presented in Table 3. Out of all relationships analyzed, five were statistically significant $(P<0.05)$, and none were significant after the Bonferroni correction was applied $(P<0.001)$. The strength of those correlations that were significant $(P<0.05)$ ranged from $r=-0.33$ to $r=0.25$. Relationships were also analyzed separately for males and females. Correlation coefficients of these subgroups were either non-significant, or of similar strength compared to the full group (coefficients not presented). In the static forward bend test two patients reached the maximum duration (900 s) of the test. This ceiling effect might influence statistics. Therefore correlations without these outliers were also calculated. This selection did not influence outcome (results not shown).

None of the performance variables associated significantly $(P<0.10)$ with more than one psychological variables. Multivariate analyses were, therefore, not performed. All psychological variables that associated significantly $(P<0.10)$ with self-reported disability were entered as predictor variables into a multivariate regression analysis (Table 4). The model explained 19\% of the variance, with kinesiophobia being the only one psychological variable that contributed significantly. Multicollinearity did not bias the model, because the average of variance inflating factors (VIF) was not substantially greater than one, and none of the VIF-values were greater than ten.

\section{Discussion}

The relationships between psychological factors and disability measures were studied in patients with CLBP. Out of all relationships analyzed, five were statistically significant at $P<0.05$, and none were significant after the Bonferroni correction was applied $(P<0.001)$. The strength of the significant correlations $(P<0.05)$ ranged from $r=-0.24$ to $r=0.33$, indicating weak relationships. The multivariate analysis revealed that psychological variables measured in this study could explain $19 \%$ of the variance of self-reported disability, with kinesiophobia

Table 4 Multivariate linear regression $(n=62)$

\begin{tabular}{llrllll}
\hline $\begin{array}{l}\text { Dependent } \\
\text { variable }\end{array}$ & Predictors & $B$ & SE & $P$ value & VIF & $r^{2}$ \\
\hline RMDQ & Constant & -4.82 & 5.53 & 0.39 & \multicolumn{2}{c}{0.19} \\
& SCL-90-R & 0.03 & 0.03 & 0.38 & 1.85 & \\
& BDI & 0.00 & 0.16 & 1.00 & 2.20 & \\
& TSK & 0.27 & 0.11 & 0.01 & 1.19 & \\
& PCL pain impact & 0.02 & 0.08 & 0.80 & 1.54 & \\
& UCL social support & 0.31 & 0.19 & 0.11 & 1.04 & \\
\hline
\end{tabular}

SCL-90-R Symptom Checklist-90-Revised, BDI Beck Depression Inventory, TSK Tampa Scale of Kinesiophobia, $P C L-E$ Pain Cognition List, experimental version, $U C L$ Utrecht's Coping List, $R M D Q$ Roland Morris Disability Questionnaire, VIF variance inflating factors

Table 3 Correlations between psychological scores and Functional Capacity Evaluation and RMDQ in patients with chronic low back pain $(n=68-92)$

\begin{tabular}{|c|c|c|c|c|c|c|}
\hline & \multicolumn{2}{|l|}{ Lifting $^{\mathrm{a}}$} & \multicolumn{2}{|c|}{ Short carry two handed ${ }^{\mathrm{a}}$} & \multirow[t]{2}{*}{ Forward bend test standing ${ }^{b}$} & \multirow[t]{2}{*}{$\mathrm{RMDQ}^{\mathrm{a}}$} \\
\hline & Men & Women & Men & Women & & \\
\hline SCL-90-R & -0.03 & 0.21 & -0.08 & 0.00 & -0.14 & $0.25 *$ \\
\hline BDI & -0.05 & 0.20 & -0.08 & 0.01 & -0.08 & $0.26^{*}$ \\
\hline ALCOS-SF & -0.06 & -0.04 & 0.08 & -0.08 & -0.10 & 0.03 \\
\hline SES & 0.02 & -0.12 & 0.05 & 0.15 & 0.05 & -0.04 \\
\hline TSK & -0.04 & -0.09 & -0.17 & -0.07 & $-0.24 *$ & $0.33 *$ \\
\hline PCL-E subscales & -0.06 to 0.24 & -0.19 to 0.10 & -0.11 to 0.18 & -0.33 to -0.02 & -0.15 to 0.08 & 0.08 to $0.24 *$ \\
\hline UCL subscales & -0.14 to $0.04^{\mathrm{a} / \mathrm{b}}$ & -0.31 to $0.20^{\mathrm{a} / \mathrm{b}}$ & -0.26 to $0.06^{\mathrm{a} / \mathrm{b}}$ & -0.04 to $0.12^{\mathrm{a} / \mathrm{b}}$ & -0.16 to 0.19 & -0.17 to 0.21 \\
\hline
\end{tabular}

SCL-90-R Symptom Checklist-90- Revised, BDI Beck Depression Inventory, ALCOS-SF General Self Efficacy Scale-Short Form, SES Rosenberg Self Esteem Scale, TSK Tampa Scale of Kinesiophobia, PCL-E Pain Cognition List, experimental version, UCL Utrecht's Coping List, $R M D Q$ Roland Morris Disability Questionnaire. Differences in $n$ : refer to text

a Pearson correlation, ${ }^{\mathrm{b}}$ Spearman correlation, applied at UCL subscales 'expression of emotions' and 'passive coping', and the static forward bend test

$* P<0.05$ 
being the only one psychological variable that contributed significantly. The overall picture that arises from this study is that relationships between psychological variables and disability in CLBP are non-existent or weak, regardless whether a performance-based or a self-report measure for disability is used.

Commonly it is assumed, that psychological factors are strongly related to disability in patients with CLBP [65]. In former research distress [57], cognitions [66], depression $[19,20]$, self efficacy and self esteem [2, 4, 36], and fear of movement/reinjury [15, 38, 62, 63] have been reported to correlate moderately to measures of functional capacity in patients with CLBP ( $r$ ranging from -0.50 to 0.59 ). Some studies, however, show moderate, weak or non-existent relationships between functional capacity and psychological factors ( $r$ ranging from -0.04 [47] to -0.37 [49] or $r^{2}$ of $34 \%$ or less [15]). Strengths of correlations between the psychological factors and disability inferred from selfreport only range between non-existing and moderate ( $r$ ranging from -0.73 to 0.59 ) $[1,2,17,21,22,33,34,42]$. Overall, reported strength of relationship between measures of psychosocial distress and measures of self-reported or performance-based disability vary from non-existent to moderate. The results of our study appear to fit in the weaker side of the strength-spectrum, indicating relative independence between psychological variables and disability as measured with an FCE or the RMDQ.

One out of five significant relationships found in this study involved a relation between psychological variables and performance testing, while four out of these five relationships involved self-reports only. This difference may be explained by the different means of testing disability: performance-based tests and self-reports appear to measure different aspects of disability $[46,55]$. Because in former research, the relationship between depression (assessed with the BDI) and disability (assessed with the Sickness impact profile (SIP) was much stronger for women than for men [33], we also analyzed the relationship for men and women. No gender differences in relationships between all measured psychological factors and performance based or self reported disability were found in our data.

The strengths of relationships reported in this study appear lower than relationships reported by most others. A possible explanation for the findings in this study may be a difference in sample characteristics. The characteristics of the patients in this study, however, show no meaningful and significant differences with other samples of patients with CLBP. The age of the studied sample is not relevantly different from other study samples [21, 33, 34, 36, 42, 47, $50,62]$. The duration of complaints is difficult to compare because of different definitions used in several studies (for example in- or excluding former episodes of pain). Mean
VAS-pain scores show no relevant differences to other studies [33, 34, 42, 47, 50, 55]. The levels of psychosocial distress (SCL-90-R) reported in this study are not relevantly different from the scores of a group unselected patients with low back pain and/or abdominal pain [41] or a group of patients with low back pain, hip- or pelvis-pain [3]. Our SCL-90-R scores are not different from other studies concerning CLBP in multidisciplinary treatment centers [31]. The BDI [22, 55], and TSK scores [34, 47, 50, $55,62]$ are also not different. The scores on the RMDQ are not relevantly different from samples studied elsewhere $[47,55]$. Because we found no meaningful differences in characteristics in the different patient groups, we concluded that our study sample represents the usual patients with CLBP. Therefore, it is unlikely that differences in study results can be attributed to a difference in patient characteristics.

Some limitations of this study have to be mentioned. Twenty-one patients did not fill out the PCL and/or UCL due to an administrative problem at the start of the study. Patient characteristics and scores on the RMDQ, however, showed no differences compared to the other patients. Therefore, including these patients in the study does not likely influence study results. Only three physical tasks of a FCE were analyzed in this study. Generalizations towards overall performance-based disability must be made with care [46]. However, as mentioned earlier, the lifting test alone has demonstrated great predictive validity of overall FCE performances in patients with CLBP [28]. The broad range of measures of psychological factors is a strength of this study. The instruments to assess the different psychosocial factors were chosen based on sufficient reliability and validity. The questionnaires appear suitable for the study and were also frequently used in former studies concerning this subject. The fact that two operational definitions of disability (both performance-based and self-report) were used can also be considered as a strength of this study.

For clinical practice it is important to unravel the components of the bio-psychosocial model and their suggested strong relationships in patients with CLBP. It has been mentioned before that despite the general conclusions about psychological factors and disability, the results of research into this issue must be interpreted cautiously [58]. In this study it is demonstrated that the suggested strong relationship cannot be confirmed with the combined use of questionnaires to assess psychological factors and an objective measure of functional capacity in an FCE as well as self-reported disability. Further research is desirable to unravel the relationship between psychological factors and disability in patients with CLBP. Additionally, further research aimed at unraveling determinants of disability in CLBP should not be restricted to psychological factors only, but include biological and social factors as well. 


\section{Conclusion}

The suggested strong relationship between psychological factors and performance-based and self-reported disability in CLBP could not be confirmed in this study. This may implicate that the relationship between psychological factors and disability is not as unambiguous as suggested for patients with CLBP.

Open Access This article is distributed under the terms of the Creative Commons Attribution Noncommercial License which permits any noncommercial use, distribution, and reproduction in any medium, provided the original author(s) and source are credited.

\section{References}

1. Arnstein P (2000) The mediation of disability by self-efficacy in different samples of chronic pain patients. Disabil Rehabil 22:794-801. doi:10.1080/09638280050200296

2. Arnstein P, Caudill M, Mandle CL, Norris A, Beasly R (1999) Self efficacy as a mediator of the relationship between pain intensity, disability and depression in chronic pain patients. Pain 80:483-491. doi:10.1016/S0304-3959(98)00220-6

3. Arrindell WA, Ettema JHM (2003) Symptom Checklist. Handleiding bij een multidimensionale psychopathologie indicator. [SCL-90. Handbook of a multidimensional psychopathology indicator]. Swets Test Publishers, Lisse (in Dutch)

4. Bandura A (1977) Self-efficacy: toward a unifying theory of behavioral change. Psychol Rev 84:191-215. doi:10.1037/0033 -295X.84.2.191

5. Beck AT, Steer RA, Garbin MG (1988) Psychometric properties of the Beck depression inventory: twenty-five years of evaluation. Clin Psychol Rev 8:77-100. doi:10.1016/0272-7358(88)90050-5

6. Bernstein IH, Jaremko ME, Hinkley BS (1994) On the utility of the SCL-90-R with low back pain patients. Spine 19:42-48. doi: 10.1097/00007632-199401000-00008

7. Beurskens AJ, De Vet HC, Koke AJ, van der Heijden GJ, Knipschild PG (1995) Measuring the functional status of patients with low back pain. Spine 20:1017-1028. doi:10.1097/00007632199505000-00008

8. Blascovich J, Tomaka J (1993) Measures of self-esteem. In: Robinson JP, Shaver PR, Wrightsman LS (eds) Measures of personality and social psychological attitudes. Institute for Social Research, pp 115-60

9. Bosscher RJ, Koning H, Meurs van R (1986) Reliability and validity of the Beck Depression Inventory in a Dutch college population. Psychol Rep 58:696-698

10. Bosscher RJ, Smit JH, Kempen GIJM (1997) Algemene competentieverwachtingen bij ouderen. Een onderzoek naar de psychometrische kenmerken van de Algemene Competentieschaal (ALCOS). Ned Tijdschr Psychol 52:239-248. Global expectations of self-efficacy in the eldery: an investigation of psychometric characteristics of the General Self-efficacy Scale (in Dutch)

11. Bouman TK, Luteijn F, Albersnagel FA, Ploeg van der FAE (1985) Enige ervaringen met de Beck Depression Inventory. Gedrag-Tijdschr Psych 13:13-24. Some experiences with the Beck Depression Inventory (in Dutch)

12. Brouwer S, Reneman MF, Dijkstra PU, Groothoff JW, Schellekens JMH, Göeken LNH (2003) Test-retest reliability of the Isernhagen work systems functional capacity evaluation in patients with chronic low back pain. J Occup Rehabil 13:207218. doi:10.1023/A:1026264519996

13. Brouwer S, Kuijer W, Dijkstra PU, Göeken LNH, Groothoff JW, Geertzen JHB (2004) Reliability and stability of the Roland Morris Disability Questionnaire: intra class correlation and limits of agreement. Disabil Rehabil 26:162-165. doi:10.1080/ 09638280310001639713

14. Brouwer S, Dijkstra PU, Stewart RE, Göeken LNH, Groothoff JW, Geertzen JHB (2005) Comparing self-report, clinical examination and functional testing in the assessment of workrelated limitations in patients with chronic low back pain. Disabil Rehabil 27:999-1005. doi:10.1080/09638280500052823

15. Crombez G, Vlaeyen JWS, Heuts PHTG, Lysens R (1999) Painrelated fear is more disabling than pain itself: evidence on the role of pain-related fear in chronic back pain disability. Pain 80:329339. doi:10.1016/S0304-3959(98)00229-2

16. Debatos G, Rondinelli RD, Cook M (2000) Functional capacity evaluation for impairment rating and disability evaluation for impairment rating and disability evaluation. In: Rondinelli RD, Katz RT (eds) Impairment rating and disability evaluation. WB Saunders, Philadelphia, pp 73-91

17. Denison E, Åsenlöf P, Lindberg P (2004) Self-efficacy, fear avoidance, and pain intensity as predictors of disability in subacute and chronic musculoskeletal pain patients in primary health care. Pain 111:245-252. doi:10.1016/j.pain.2004.07.001

18. Duckro PN, Margolis RB, Tait RC (1985) Psychological assessment in chronic pain. J Clin Psychol 41:499-504. doi: 10.1002/1097-4679(198507)41:4<499::AID-JCLP2270410408> 3.0.CO;2-F

19. Geisser ME, Haig AJ, Theisen ME (2000) Activity avoidance and function in persons with chronic back pain. J Occup Rehabil 10:215-227. doi:10.1023/A:1026666403039

20. Geisser ME, Robinson ME, Miller QL, Bade SM (2003) Psychosocial factors and functional capacity evaluation among persons with chronic pain. J Occup Rehabil 13:259-276. doi: 10.1023/A:1026272721813

21. Genêt F, Lapeyre E, Schnitzler A, Hausseguy A, D’Apolito AC, Lafaye de Michaux R et al (2006) Evaluation psychocomportementale dans la lombalgie chronique. Ann Readapt Med Phys 49:226-233. Psychobehavioural assessment for chronic low back pain. doi:10.1016/j.annrmp.2006.03.002 (in French)

22. Gesztelyi G, Bereczki D (2006) Determinants of disability in everyday activities differ in primary and cervicogenic headaches and in low back pain. Psychiatry Clin Neurosci 60:271-276. doi: 10.1111/j.1440-1819.2006.01501.x

23. Goubert L, Crombez G, Vlaeyen JW, Damme s van, Broeck A van den, Houdenhove B van (2000) De Tampa schaal voor kinesiofobie: Psychometrische karakteristieken en normering. Gedrag Gezond 28:54-62. The Tampa Scale for kinesiophobia. Psychometric characteristics and norms (in Dutch)

24. Gross DP, Battie MC (2002) Reliability of safe maximum lifting determinations of a functional capacity evaluation. Phys Ther 82:364-371

25. Gross DP, Battie MC (2003) Construct validity of a kinesiophysical functional capacity evaluation administered within a worker's compensation environment. J Occup Rehabil 13:287295. doi:10.1023/A:1026276822721

26. Gross DP, Battie MC, Cassidy JD (2004) The prognostic value of functional capacity evaluation in patients with chronic low back pain: part I: timely return to work. Spine 29:914-919. doi: 10.1097/00007632-200404150-00019

27. Gross DP, Battie MC (2004) The prognostic value of functional capacity evaluation in patients with chornic low back pain: part 2 : sustained recovery. Spine 29:920-924. doi:10.1097/00007632200404150-00020 
28. Gross DP, Battie MC, Asante A (2006) Development and validation of a short-form functional capacity evaluation for use in claimants with low back disorders. J Occup Rehabil 16:53-62. doi:10.1007/s10926-005-9008-x

29. Hazard RG, Haugh LD, Reid S (1996) Early prediction of chronic disability after occupational low back injury. Spine 21:945-951. doi:10.1097/00007632-199604150-00008

30. Hope P, Forshaw M (1999) Assessment of psychological distress is important in patients presenting with low back pain. Physiotherapy 85:563-570. doi:10.1016/S0031-9406(05)61250-3

31. Hutten MMR, Hermens HJ, IJzerman MJ, Lousberg R, Zilvold G (1999) Distribution of psychological aspects in subgroups of chronic low back pain patients divided on the score of physical performance. Int J Rehabil Res 22:261-268. doi:10.1097/ 00004356-199912000-00002

32. Isernhagen Work Systems (1997) Functional Capacity procedure manual. Duluth, MN

33. Keogh E, McCracken LM, Eccleston C (2006) Gender moderates the association between depression and disability in chronic pain patients. Eur J Pain 10:413-422. doi:10.1016/j.ejpain.2005. 05.007

34. Koho P, Aho S, Watson P, Hurri H (2001) Assessment of chronic pain behavior: reliability of the method and its relationship with perceived disability, physical impairment and function. J Rehabil Med 33:128-132. doi:10.1080/165019701750165970

35. Kuijer W, Brouwer S, Schiphorst Preuper HR, Groothoff JW, Geertzen JHB, Dijkstra PU (2005) Work status and chronic low back pain: exploring the International classification of functioning, disability and health. Disabil Rehabil 28:379-388. doi: 10.1080/09638280500287635

36. Lackner JM, Carosella AM (1999) The relative influence of perceived pain control, anxiety, and functional self efficacy on spinal function among patients with chronic low back pain. Spine 24:2254-2261. doi:10.1097/00007632-199911010-00014

37. Lee CE, Simmonds MJ, Novy DM, Jones S (2001) Self reports and clinician-measured physical function among patients with low back pain: a comparison. Arch Phys Med Rehabil 82:227231. doi:10.1053/apmr.2001.18214

38. Lethem J, Slade PD, Troup JDG, Bently G (1983) Outline of a fear-avoidance model of exaggerated pain perception-I. Behav Res Ther 21:401-408. doi:10.1016/0005-7967(83)90009-8

39. Linton SJ (2000) A review of psychological risk factors in back and neck pain. Spine 25:1148-1156. doi:10.1097/00007632200005010-00017

40. Love AW (1987) Depression in chronic low back pain patients: diagnostic efficiency of three self-report questionnaires. J Clin Psychol 43:84-89

41. Meeuwesen L, Arrindell WA, Huyse FJ (1992) Psychometrische kwaliteiten van de Symptom Checklist (SCL-90) bij poliklinische patiënten met buikpijn of lage rugklachten. T Soc Gezondheidsz 70:123-131 in Dutch

42. Meredith P, Strong J, Feeney J (2006) Adult attachment, anxiety, and pain self-efficacy as predictors of pain intensity and disability. Pain 123:146-154. doi:10.1016/j.pain.2006.02.025

43. Nachemson AL, Jonsson E (2000) Neck and back pain. The scientific evidence of causes, diagnosis and treatment. Lippincott Williams \& Wilkins, Philadelphia, pp 57-78

44. Pincus T, Burton AK, Vogel S, Field AP (2002) A systematic review of psychological factors as predictors of chronicity/disability in prospective cohorts of low back pain. Spine 27:109120. doi:10.1097/00007632-200203010-00017

45. Portney LG, Watkins MP (2000) Part IV Data analysis: correlation. 2000. Foundations of clinical research. Applications to practice, 2nd edn. Prentice Hall Health, Upper Saddle River, p 503
46. Reneman MF, Jorritsma W, Schellekens JM, Goeken LNH (2002) Concurrent validity of questionnaire and performance based disability measurements in patients with chronic aspecific low back pain. J Occup Rehabil 12:119-129. doi:10.1023/ A:1016834409773

47. Reneman MF, Jorritsma W, Dijkstra SJ, Dijkstra PU (2003) Relationship between kinesiophobia and performance in a functional capacity evaluation. J Occup Rehabil 13:277-285. doi: 10.1023/A:1026224805883

48. Reneman MF (2004) Functional capacity evaluation in patients with chronic low back pain. Reliability and validity. Thesis. University of Groningen. Line up tekstprodukties bv, Groningen

49. Reneman MF, Schiphorst Preuper HR, Kleen M, Geertzen JHB, Dijkstra PU (2007) Are pain and pain related fear related to performances in a functional capacity evaluation in patients with chronic low back pain? J Occup Rehabil 17:247-258. doi: 10.1007/s10926-007-9078-z

50. Roelofs J, Goubert L, Peters M, Vlaeyen JWS, Crombez G (2004) The Tampa Scale for Kinesiophobia: further examination of psychometric properties in patients with chronic low back pain and fibromyalgia. Eur J Pain 8:495-502. doi:10.1016/j.ejpain. 2003.11.016

51. Roland M, Morris R (1983) A study of the natural history of low back pain: Part 1. Development of a reliable and sensitive measure of disability in low back pain. Spine 8:141-144. doi: 10.1097/00007632-198303000-00004

52. Roland M, Fairbank J (2000) The Roland-Morris Disability Questionnaire and the Owestry Disability Questionnaire. Spine 25:3115-3124. doi:10.1097/00007632-200012150-00006

53. Schiphorst Preuper HR, Reneman MF, Boonstra AM, Dijkstra PU, Versteegen GJ, Geertzen JHB (2007) The relationship between psychosocial distress and disability assessed by the SCL90-R and RMDQ in patients with chronic low back pain. Spine J 7:525-530. doi:10.1016/j.spinee.2006.08.016

54. Schreurs PJG, van de Willige G, Brosschot JF, Tellegen B, Graus GMH (1993) De Utrechtse Coping Lijst: UCL Omgaan met problemen en gebeurtenissen, herziene handleiding [The Utrecht's Coping List: UCL. Managing problems and events revised manual]. Swets Test Publishers, Lisse (in Dutch)

55. Smeets RJEM, van Geel ACM, Kester ADM, Knottnerus JA (2007) Physical capacity tasks in chronic low back pain: What is the contributing role of cardiovascular capacity, pain and psychological factors? Disabil Rehabil 29:577-586. doi:10.1080/ 09638280600925829

56. Tomas JM, Oliver A (1999) Rosenberg's Self-Esteem Scale: two factors or method effects. Structural Equation Modeling 6:84-98

57. Truchon M (2001) Review. Determinants of chronic disability related to low back pain: Towards an integrative biopsychosocial model. Disabil Rehabil 23:758-767. doi:10.1080/09638280 110061744

58. Turk DC, Okifuji A (2002) Psychological factors in chronic pain: Evolution and revolution. J Consult Clin Psychol 70:678-690. doi:10.1037/0022-006X.70.3.678

59. Turner JA, Fulton-Kehoe D, Franklin G, Wickizer TM, Wu R (2003) Comparison of the Roland-Morris Disability Questionnaire and generic health status measures: a population-based study of workers' compensation back injury claimants. Spine 28:1061-1067. doi:10.1097/00007632-200305150-00019

60. Vlaeyen JW, Geurts SM, van Eek H, Snijders AMJ, Shuerman JA, Groenman NH (1989) Pijn cognitielijst, Experimentele versie [Pain Cognition List. experimental version]. Swets en Zeitlinger, Lisse (in Dutch)

61. Vlaeyen JW, Geurts SM, Kole-Snijders AMJ (1990) What do chronic pain patients think of their pain? Towards a pain cognition questionnaire. Br J Clin Psychol 29:383-394 
62. Vlaeyen JWS, Kole-Snijders AMJ, Boeren RGB, van Eek H (1995) Fear of movement/(re)injury in chronic low back pain and its relation to behavioral performance. Pain 62:363-372. doi: 10.1016/0304-3959(94)00279-N

63. Vlaeyen JWS, Kole-Snijders AMJ, Rotteveel AM, Ruesink R, Heuts PHTG (1995) The role of fear of movement/ (re)injury in pain disability. J Occup Rehabil 5:235-252. doi:10.1007/ BF02109988

64. Vlaeyen JWS, van Breukelen GJP, Nooyen-Haazen IWCJ, Stomp-VandenBerg SGM, Kole-Snijders AMJ (2003) Pijn
Cognitie Lijst-2003 [Pain Cognition List-2003]. Academisch Ziekenhuis Maastricht, Pijn Kennis Centrum [University Hospital Maastricht Pain Knowledge Center]. Maastricht, The Netherlands (in Dutch)

65. Waddell G (2004) The back pain revolution, 2nd ed edn. Elsevier Limited, London

66. Walsh DA, Radcliffe JC (2002) Pain beliefs and perceived physical disability of patients with chronic low back pain. Pain 97:23-31. doi:10.1016/S0304-3959(01)00426-2 